\title{
The Influence of Pillar Form to Local Mechanism
}

\author{
Sarra Rahmadani ${ }^{1}$, Syarvina $^{2}$ \\ \{sarra_ft@unimed.ac.id ${ }^{1}$, syarvina@gmail.com² \\ Universitas Negeri Medan, Indonesia ${ }^{1}$ \\ Universitas Sumatera Utara, Indonesia ${ }^{2}$ \\ Sarra-ft@unimed.ac.id
}

\begin{abstract}
Basically, rivers have a dynamic flow character that often causes changes in flow morphology. The pillar is one form of water that can affect changes in flow patterns, because its presence obstructs river flow. Changes in flow patterns that occur can result in scouring around the pillars. The purpose of this study to determine the effect of a pillar of the local scour potential that occur around the pillar with the discharge, Q $=1.0$ liter/ $\mathrm{s}$ and know the pattern and depth of scour around the pillar. The study was conducted on permanent uniform flow conditions with variations in the shape of the pillars. The pillar shape variations used are cylinder, rectangular and rectangular wide shape nose. The study was conducted at the Laboratory of civil engineering hydraulics, Universitas Sumatera Utara (USU), using a flume (length: $8 \mathrm{~m}$, height: $0.3 \mathrm{~m}$ and width: $0.076 \mathrm{~m}$ ). The material used in the form of sand, with model tested for 250 minutes for running. The observation results obtained the value of the maximum scour depth on the cylinder, rectangular and rectangular wide shape nose with discharge, $\mathrm{Q}=1.0$ liter/ $\mathrm{s}$ respectively are $25 \mathrm{~mm}, 30 \mathrm{~mm}$, and $39 \mathrm{~mm}$.
\end{abstract}

Keywords: Discharge, Local Scour, Pillar.

\section{Introduction}

The process of scouring on rivers can occur due to the influence of the building of water around the river. The water building can be a pillar of a bridge. Because of the existence of pillar, causing the river flow is blocked. This can result in scouring/ erosion and sediment/ deposition deposits around the pillars. In addition, there is also a change in flow characteristics such as flow velocity and turbulence that causes changes in sediment transport.

The scouring that occurs around the pillar is the influence of the vortex system that arises due to an obstacle to flow by the pillar. When the flow approached the pillar, the pressure will decrease and stagnation causing downward flow (down flow) or a stream of high velocity into a low speed. This down flow reaches a maximum peak when it is at the bottom of the channel.

From various variations of pillar shapes such as cylinder, rectangular, rectangular with semicircular ends, rectangular wide shape nose, lenticular and ellipse front sides can have a different effect on flow patterns. Cylinder, rectangular and rectangular wide shape nose are forms of various variations of pillar shapes that are often used in bridge construction planning, because in terms of pillar shape itself it is quite easy in the manufacturing process and in theory ticks, scouring that occurs on rectangular pillars bigger than a pillar with a flat front side. The purpose of this study was to determine the influence of a pillar of the local scour 
around the pillar, obtain a picture of the development process and getting crushed against time to scour pattern around the pillars with a constant discharge $(\mathrm{Q}=1.0$ liter/ $\mathrm{s})$.

This study has the following limitations:

- Variation of pillar models: cylinder, rectangular and rectangular wide shape nose

- Scour behavior reviewed around the pillar

- The material used in this study is sand

- The observed flow pattern is a three-dimensional contour pattern with measurements of the $\mathrm{x}, \mathrm{y}$ and $\mathrm{z}$ direction depth.

- The flow used is flow without any sediment content (clear water scour).

- The effect of the flume boundary wall on the scour that occurs is not taken into account.

- Using a flume with a length: $8 \mathrm{~m}$, height: $0.3 \mathrm{~m}$ and width: $0.076 \mathrm{~m}$.

\section{Scouring} namely:

The eruption can be divided into three sections according to Ettema and Raudkivi [1][2]

a) General scouring, scouring that occurs as a result of natural processes and not at all related to the presence or absence of river buildings.

b) Scouring is localized (constriction scour), scouring caused by narrowing of the river channel so that the flow becomes centralized.

c) Local scour is a direct result of the structure in the river channel.

Where local scouring according to Yulistiyanto [3] is a scour that occurs around the bridge or pillar abutments, caused by a vortex system due to interference with the flow pattern due to obstacles. Pillar approach flow and stagnation pressure will decrease and cause a down flow that flows from the high speed becomes low. The strength of down flow will reach its maximum when it is right at the bottom of the channel.

According to Hanwar [4], the scour mechanism around the bridge pillar is when the sediment particles covering the pillar start to move, then the scour process begins to form. These eroded particles will follow the flow pattern and bottom from near the pillar towards the bottom of the river. Furthermore, if these sediment particles are more eroded then the scouring will reach maximum depth. Factors influencing scour depths such as flow velocity in river basins, sediment gradation, pillar size and grain size of base material, river bed depth from water level, pillar position, and pillar shape.

\section{The scour equation for regular flow}

Depth of scour depends on several variables [5], namely the characteristics of liquid, base material, flow in the channel and the shape of the bridge pillar written ys $=f(\rho, v, g, d, \rho s$, yo, $\mathrm{U}, \mathrm{b})$. In clear water conditions for the depth of grinding can be calculated through the equations of Raudkivi [1], as stated in equation (1) below:

$$
y s e=2.3 K \sigma K s K \alpha K d t K d
$$

$K d$ : flow height factor

$K s:$ pillar form factor

$K d t$ : pillar size factor

$K \alpha$ : pillar position factor

$K \sigma$ : function of the geometric standard deviation of the particle size distribution

$\alpha$ : angle comes flow 
In Melville and Sutherland (1988) explained, that the depth of scouring of local scour, ys, on the pillar can be written in equation (2):

$$
\text { yse }=\mathrm{K}_{\mathrm{I}} \mathrm{K}_{\sigma} \mathrm{K}_{\mathrm{s}} \mathrm{K}_{\alpha} \mathrm{K}_{\mathrm{dt}} \mathrm{K}_{\mathrm{d}}
$$

$K d$ : flow height factor

$K I$ : flow intensity factor

$K s:$ pillar form factor

$K \alpha$ : pillar position factor $[0.78(y o / b) 0.225]$

$K d t$ : pillar size factor

$K \sigma$ : function of the geometric standard deviation of the particle size distribution

Information:

$\mathrm{K}_{\mathrm{I}}=2,4(\mathrm{U} / \mathrm{Uc})$ if $(\mathrm{U} / \mathrm{Uc})<1$

$\mathrm{K}_{\mathrm{I}}=2.4$ if $(\mathrm{U} / \mathrm{Uc})>1$

\section{Research Method}

The study was conducted at the Hydraulic Laboratory of the Department of Civil Engineering, Faculty of Engineering, University of North Sumatera (USU), using Recirculating sediment flume (Figure 1), with position model of a pillar made of wood. The pillar model (Figure 2) is placed in the middle of the flume at a distance of $3.5 \mathrm{~m}$ from the upstream and then arranged with sand material that has been spread along the flume. This research was conducted by regulating discharge, $\mathrm{Q}=1.0$ liter/ $\mathrm{s}$.

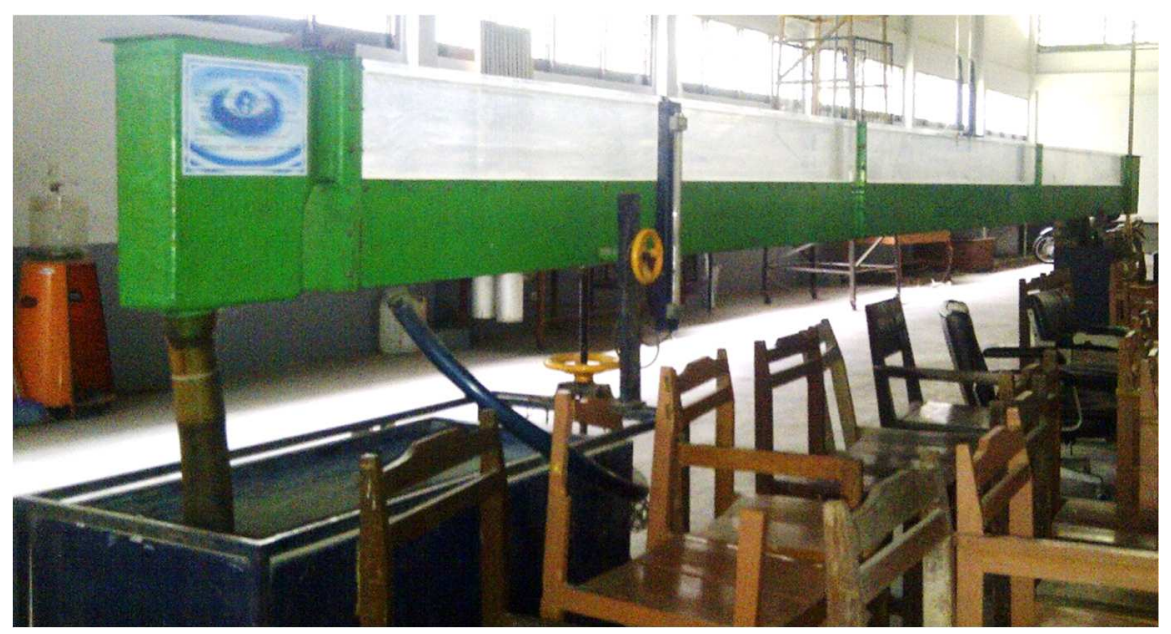

Fig 1. Recirculating sediment flume. 

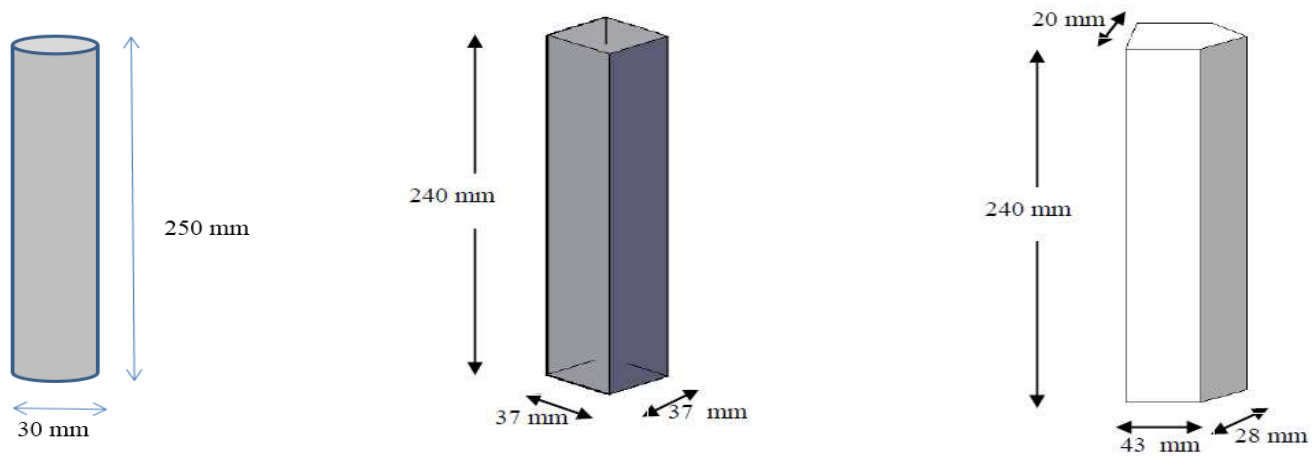

Fig 2. Pillar Model

Observation process scour depth is done by noting the depth of scouring of the early running for a specified time, that is 1-10 minutes recorded every interval of 1 minute, 10 - 40 minute interval is recorded every 5 minutes, $40-70$ minutes are recorded each interval of 10 minutes, 70 - 250 minutes are recorded at 15-minute intervals. Observation of scour depth is recorded continuously during equilibrium time.

The contour data taken is scour contour data around the pillar. Where the data is measured after running has been completed. You do this by slowly reducing discharge so that scouring around the pillar is not disturbed by changes in the discharge. After that, three dimensional measurements were taken and the sand was leveled again. So, the process runs like that done in return again with the form of the next pillar.

\section{Results and Discussion}

Measurements on the development of local scour depth and contour data of scouring that occurs around the pillar performed through visual observation and measurement methods it uses the tool point gauge. Measurement contour data is then processed using a software, which is a surfer to get a surface contour display around the pillar.

\subsection{The depth scour on cylinder pillar against time}

Measurement of scour depth development of the time around the pillars of the cylinder is done at 8 observation point as shown in Figure 3 below: 


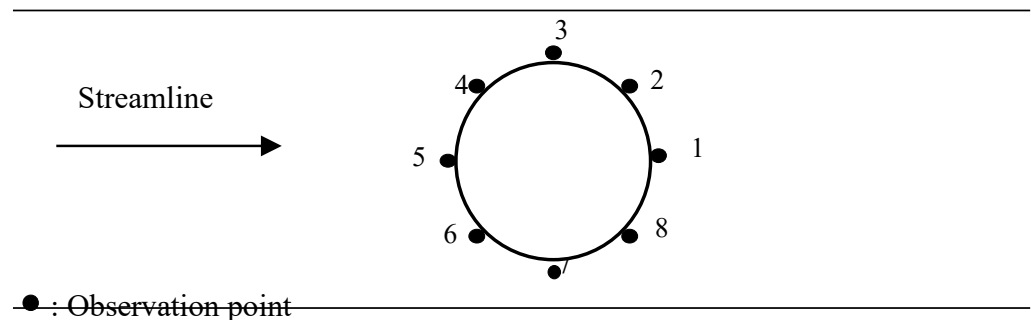

Fig 3. Position of cylinder pillar observation points

The results of observations of the scour depth to time on the cylinder pillar with discharge, $\mathrm{Q}=1.0$ liter/s, are shown in Figure 4, which shows the relationship of scour depth to time.

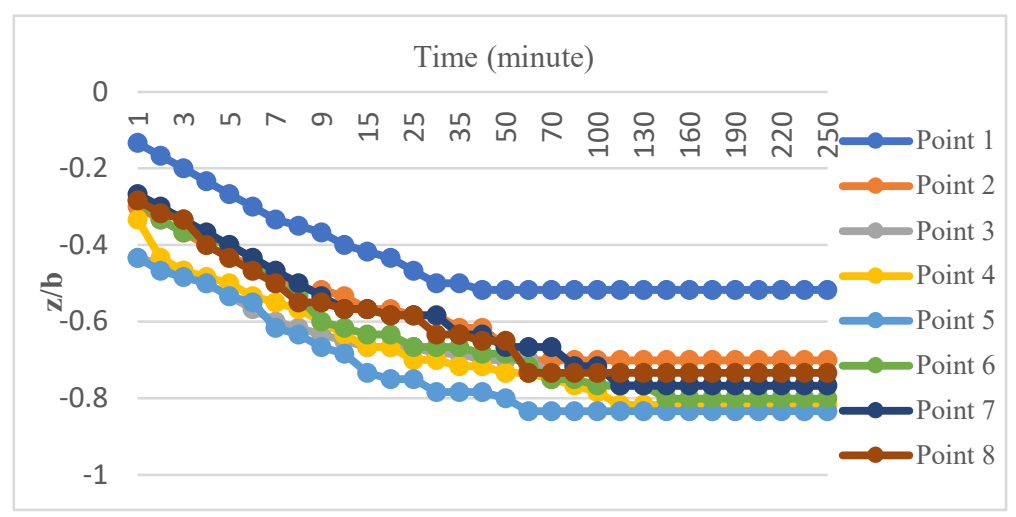

Fig 4. Development of scour depth with respect to time on a cylinder pillar

In Figure 4 it is shown that point 1 is the point that experiences the greatest scour depth compared to other observation points, while point 5 is the point that experiences the smallest scour depth. This happens because of the location of the pillar.

\subsection{The depth scour on rectangular pillar against time}

Measurement of scour depth development of the time around the pillars rectangular performed at 8 observation point as shown in Figure 5 below:

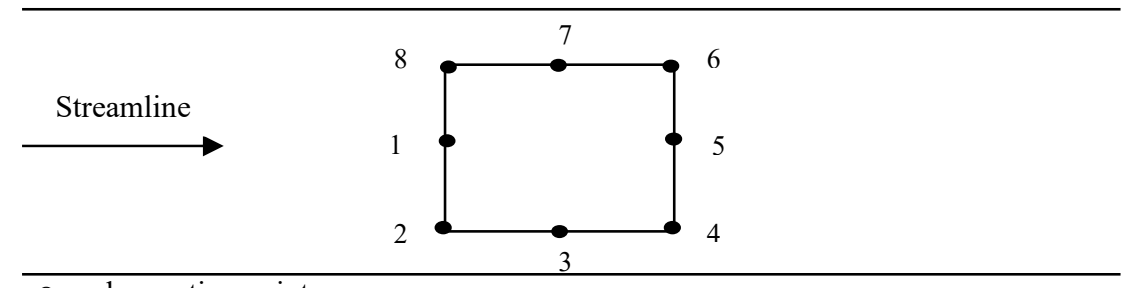

- observation point

Fig 5. Position of observation points of a rectangular pillar 
The results of observed scour depth to time on a rectangular pillar with a discharge, $\mathrm{Q}=$ 1.0 liter/ s, are shown in Figure 6, which shows the relationship of scour depth to time.

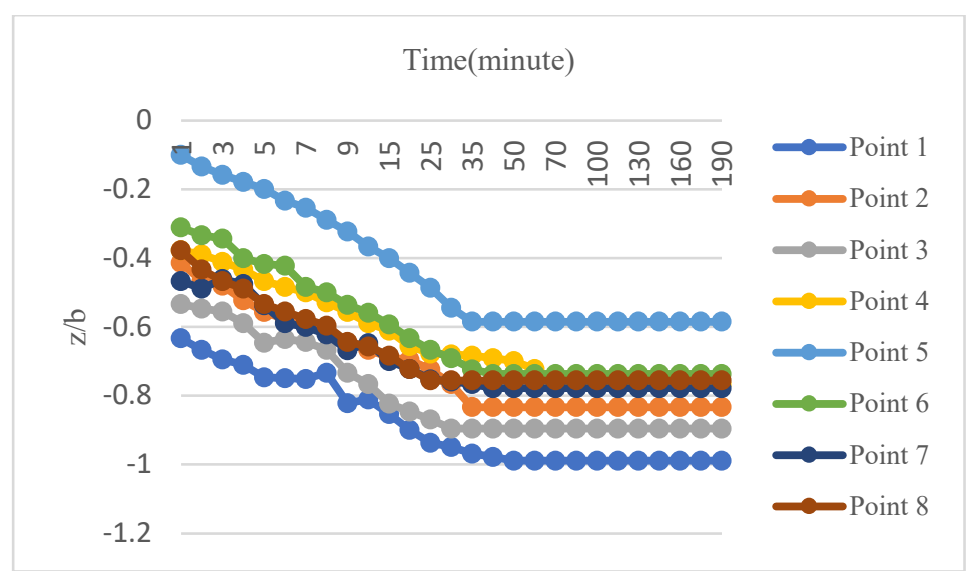

Fig 6. Development of scour depth with time on a rectangular pillar

The greatest scour development occurred at the observation point 1 as shown in Figure 6. The point are the pillars of the front, while the development of scours the smallest pitch so at the observation point 5 which is the pillar of the back.

\subsection{The depth scour on rectangular wide shape nose pillar against time}

Measurement of the development of scour depth with respect to time around a rectangular wide shape nose pillar is performed at 8 points of observation as shown in Figure 7 below:

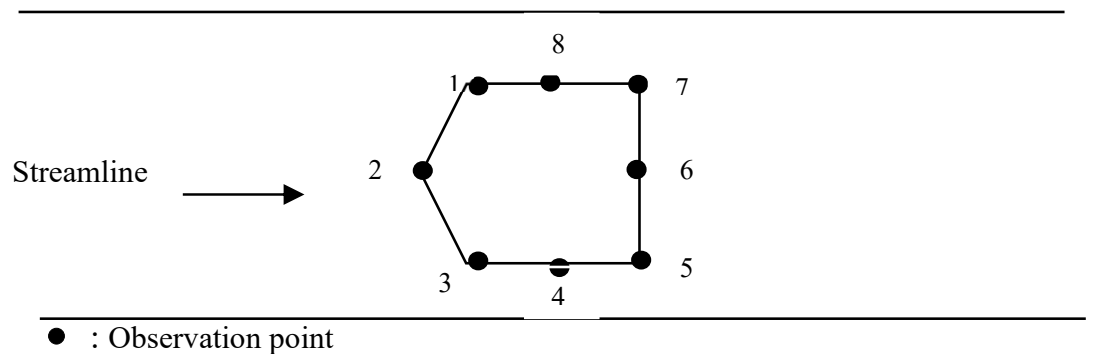

- : Observation point

Fig 7. Position of the observation point of a rectangular wide shape nose pillar

The results of observed scour depth to time on a rectangular wide shape nose pillar at discharge, $\mathrm{Q}=1.0$ liter/ s, are shown in Figure 8, which shows the relationship of scour depth to time. 


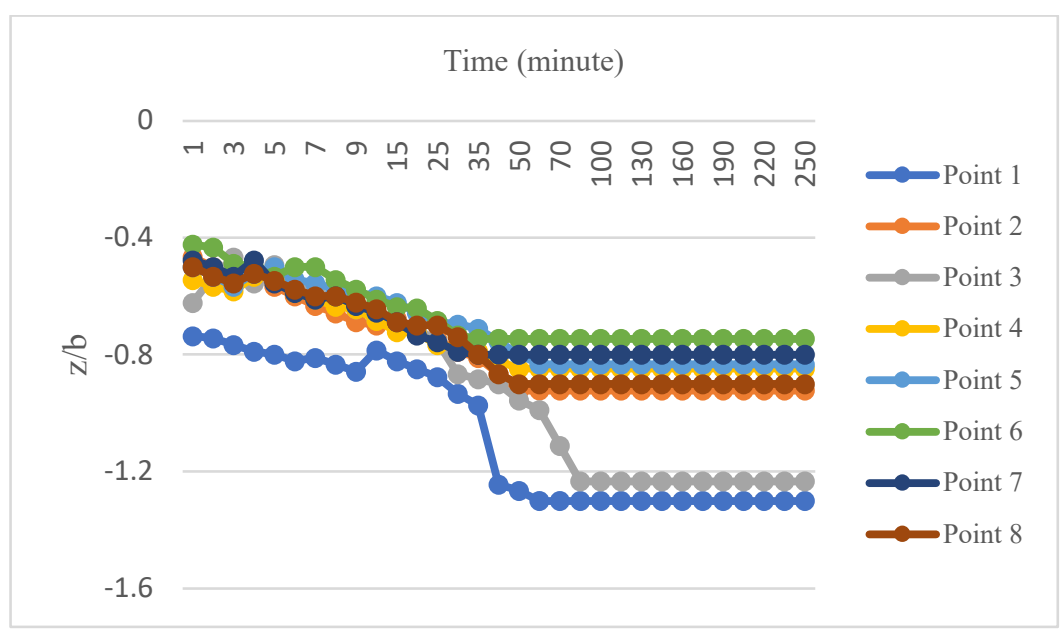

Fig 8. Development of scour depth with time on a rectangular wide shape nose pillar

At figure 8 shows that the largest scour development achieved at the point of observation 1 where in the position is almost the same as the third point is on the side of the front pillar. The smallest scouring development is achieved at observation point 6 located behind the pillar, resulting in the accumulation of sand material.

Of the three pillar shapes tested, there was a similarity regarding the position of the observation point where on the observation side the front of the pillar experienced the deepest scouring. It is caused by factors stream which initially directly on the front side pillars point and opposite on the back side of the pillar will occur accumulation of sand material because it does not impact directly streaming. From the sides of the jetting pillar it forms a proper pile up at the observation point behind the pillar.

The following Table 1 that shows the value of the depth of scour maximum each pillar shape with an 8 point observations.

Table 1. Maximum scour depth around pillars as a function of pillar shape variation.

\begin{tabular}{lccccccccc}
\hline Shape & \multicolumn{7}{c}{ Depth of Scour Ds/ b Observation Point } \\
\hline Observation & 1 & 2 & 3 & 4 & 5 & 6 & 7 & 8 \\
Point & & & & & & & & \\
Cylinder & $-0,516$ & $-0,700$ & $-0,766$ & $-0,816$ & $-0,833$ & $-0,800$ & $-0,766$ & $-0,733$ \\
Rectangular & -0.988 & $-0,833$ & $-0,895$ & $-0,767$ & $-0,584$ & $-0,736$ & -7777 & $-0,755$ \\
Rectangular wide & -1.3 & $-0,922$ & -1 & $-0,847$ & $-0,833$ & $-0,745$ & -0.8 & -0.9 \\
shape nose & & & & & & & & \\
\hline
\end{tabular}

Source: Observation Results

From Table 1 it appears that the maximum scour depth value of the three pillar shapes occurs in the shape of a rectangular wide shape nose pillar, precisely at observation point 1 which is -1.3 . The maximum scour depth that occurs in the cylinder pillar is $25 \mathrm{~mm}$, the rectangular pillar is $30 \mathrm{~mm}$, and for the rectangular wide shape nose pillar is $39 \mathrm{~mm}$. 


\subsection{Scour pattern around the pillar cylinder}

Contour measurement is done by point gauge and contour coordinate taking, namely for $\mathrm{X}$ perpendicular to the direction of flow (horizontal), $\mathrm{Y}$ in the direction of flow and $\mathrm{Z}$ perpendicular to the direction of flow (vertical). The scour depth ( $Z$ direction) is measured by the interval of the distance for the $\mathrm{X}$ direction of $1 \mathrm{~cm}$ and for the $\mathrm{Y}$ direction of $1 \mathrm{~cm}$. Point reading gauge produce point of depth ( $\mathrm{Z}$ direction) of each coordinate directions $\mathrm{X}$ and $\mathrm{Y}$ directions on the surface of the base material with different patterns of scouring in every variation pillar. Furthermore, the data and measurement results are processed to obtain a contour map using the surfer program.

Figure 9 shows an illustration of the cylinder pillar seen above on the flume.

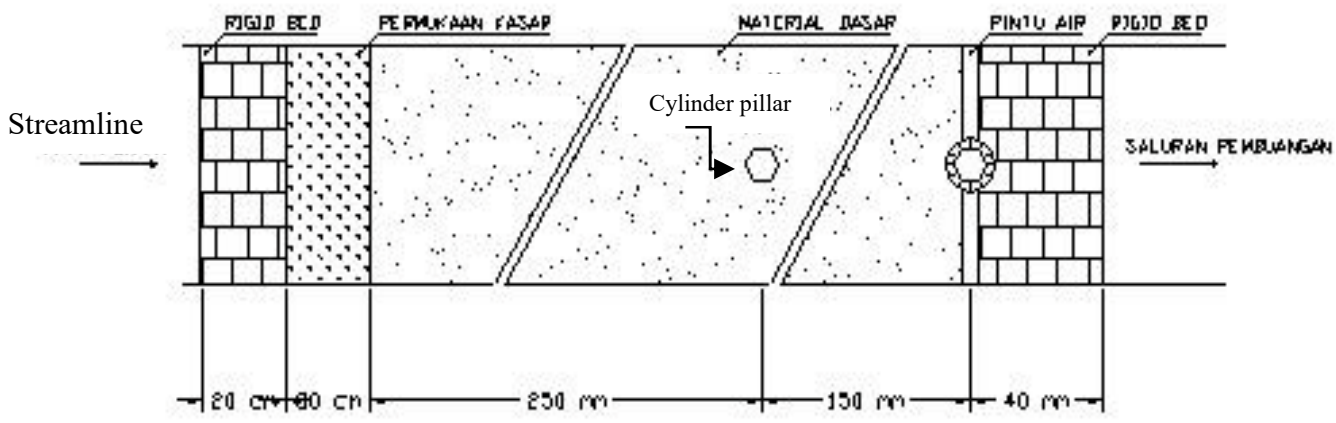

Fig 9. Top view of cylinder pillar on flume (without scale)

Figure 10 below shows the results of the contours of the scour formed around the cylinder pillars by the surfer program. With this Surfer program, it can also be seen as isometry of the scouring of the cylinder pillars as shown in Figure 11.

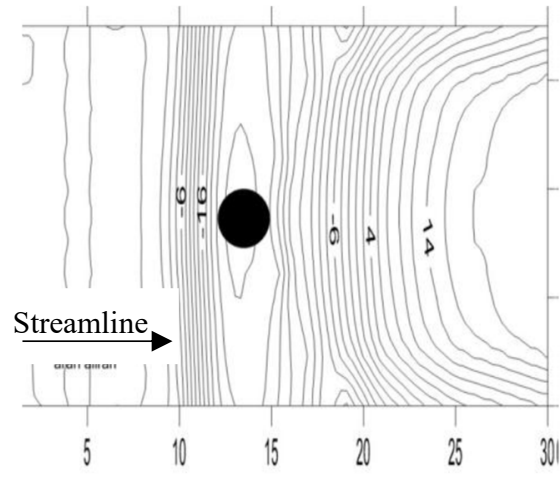

Fig 10. Contour scour pattern cylinder pillar

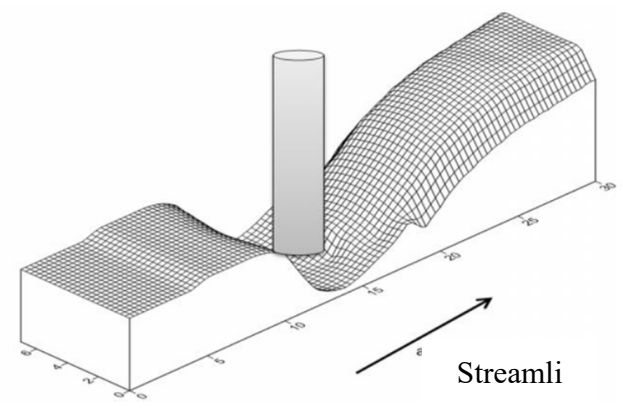

Fig 11. Isometry scour patterns cylinder pillar

The isometric figure the scouring pattern of the cylinder pillar is clearly visible local scouring that occurs around the pillar, which displays the largest scour in the direction of flow. 


\subsection{Patterns of scouring around the rectangular pillar}

Figure 12 is a sketch of an image showing the placement of a rectangular pillar on the flume.

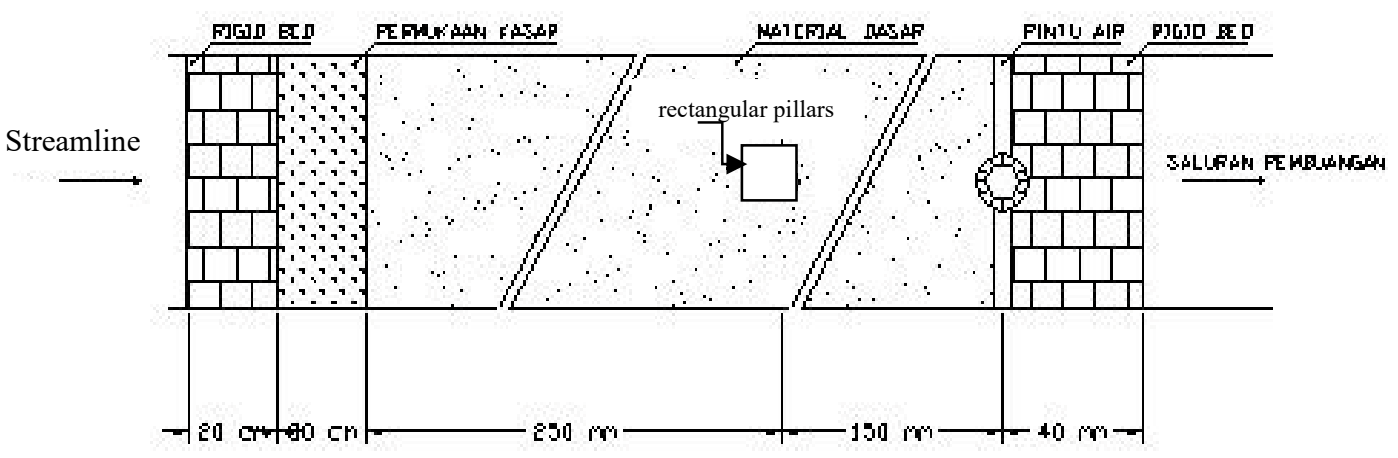

Fig 12. Top view of rectangular pillars on the flume (without scale)

Generally, the scour pattern that occurs in this rectangular pillar is relatively the same as the cylinder pillar, which starts from the flow originating from the upstream which is blocked by the pillar, which can cause a vortex that occurs due to the velocity of the flow that hits the front pillar into a compressive force on the pillar surface. The vortex which diminishes from the front pillar and then grind the side pillar and local scour on the pillar. For contour patterns of scour and isometry pillars of rectangular can be seen in Figure 13 and Figure 14.

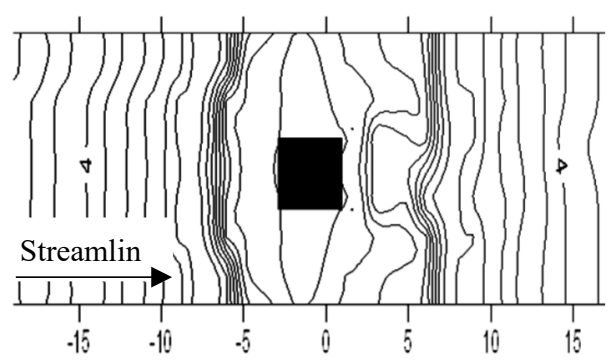

Fig 13. Contour scour pattern rectangular pillar

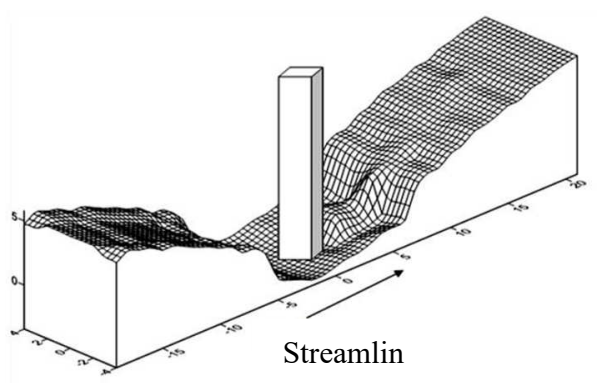

Fig 14. Isometry scour patterns rectangular pillar

In Figure 14, it can be seen clearly the accumulation of material behind the rectangular pillar, this is caused by the flow that flows obstructed by the pillar, the obstruction causes the material to not be carried towards the downstream (sediment) flow.

\subsection{Patterns of scouring around the rectangular wide shape nose pillar}

Sketch of the placement of a rectangular wide shape nose pillar of the flume can be seen in the following Figure 15: 


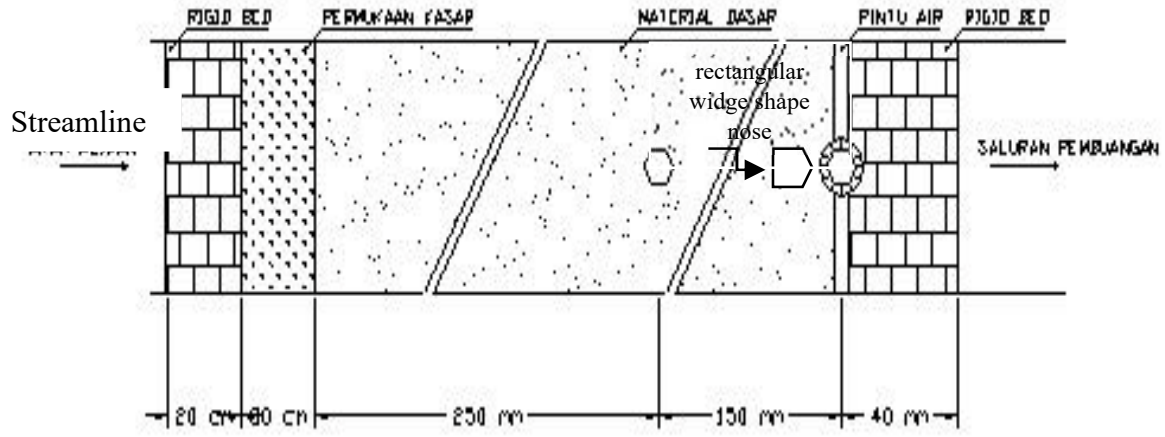

Fig 15. Top view of the rectangular wide shape nose pillar of the flume (without scale)

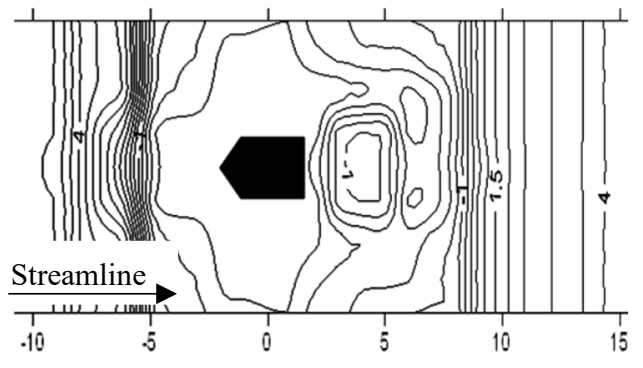

Fig 16. Contour scour pattern rectangular wide shape nose pillar

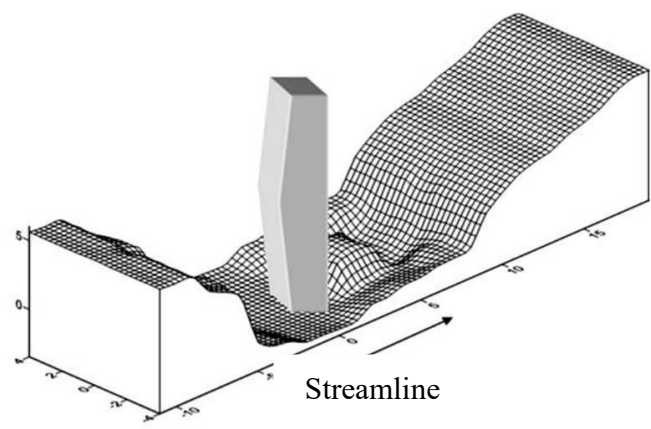

Fig 17. Isometry scour patterns rectangular wide shape nose pillar

In general, the scour patterns that occur in the three pillar shapes are relatively the same. Starting from a stream originating from the upstream that is blocked by the presence of a pillar, can cause a vortex that occurs due to the velocity of the flow that hits the front pillar into a compressive force on the surface of the pillar. Vortex which eroded part front pillar and then grind the side pillar and local scour on the pillar.

\subsection{Calculation local scour depth according to the equation Raudkivi (1991)}

\section{Cylinder pillar}

$\mathrm{K} \sigma=0.8 ; \mathrm{Ks}=1.0 ; \mathrm{K} \alpha=1.0 ; \mathrm{Kdt}=0.95 ; \mathrm{Kd}=1.0$

y se $=2.3 \mathrm{K \sigma} K s \mathrm{K \alpha} K d t \mathrm{Kd}$

$=2.3 \times 0.8 \times 1.0 \times 1.0 \times 0.95 \times 1.0=1.784$

\section{Rectangular pillar}

$\mathrm{K} \sigma=0.8 ; \mathrm{Ks}=1.22 ; \mathrm{K} \alpha=1.0 ; \mathrm{Kdt}=1.0 ; \mathrm{Kd}=0.55$

y se $=2.3 K \sigma K s$ Ka Kdt Kd

$=2.3 \times 0.8 \times 1.22 \times 1.0 \times 1.0 \times 0.55=1.235$ 


\section{Rectangular widge shape nose pillar}

$\mathrm{K} \sigma=0.8 ; \mathrm{Ks}=0.76 ; \mathrm{K} \alpha=1.0 ; \mathrm{Kdt}=1.0 ; \mathrm{Kd}=0.55$

$y s e=2.3 K \sigma K s K \alpha K d t K d$

$=2.3 \times 0.8 \times 0.76 \times 1.0 \times 1.0 \times 0.55=0.769$

\subsection{Depth scours according to the equation Melville and Sutherland (1998)}

\section{Cylinder pillar}

Because the value $(\mathrm{U} / \mathrm{Uc})=0.447$

$(\mathrm{U} / \mathrm{Uc})<1$ then the value of $\mathrm{K}_{\mathrm{t}}=2.4 \mathrm{x}(\mathrm{U} / \mathrm{Uc})$

$\mathrm{K}_{\mathrm{I}}=2.4 \times 0.447=1.0728$

$\mathrm{K} \sigma=0.8 ; \mathrm{Ks}=1.0 ; \mathrm{K} \alpha=1.0 ; \mathrm{Kdt}=0.95 ; \mathrm{Kd}=1.0$

$y s e=\mathrm{K}_{1} \mathrm{~K} \sigma \mathrm{Ks} \mathrm{K} \alpha \mathrm{Kdt} \mathrm{Kd}$

$=1.0728 \times 0.8 \times 1.0 \times 1.0 \times 0.95 \times 1.0=0.815$

\section{Rectangular pillar}

Because the value $(\mathrm{U} / \mathrm{Uc})=0.43$

$(\mathrm{U} / \mathrm{Uc})<1$ then the value of $\mathrm{K}_{1}=2.4 \mathrm{x}(\mathrm{U} / \mathrm{Uc})$

$\mathrm{K}_{\mathrm{I}}=2.4 \times 0.43=1.032$

$\mathrm{K} \sigma=0.8 ; \mathrm{Ks}=1.22 ; \mathrm{K} \alpha=1.0 ; \mathrm{Kdt}=1.0 ; \mathrm{Kd}=0.55$

$y s e=\mathrm{K}_{1} \mathrm{~K} \sigma \mathrm{Ks} \mathrm{K} \alpha \mathrm{Kdt} \mathrm{K} \mathrm{d}$

$=1,032 \times 0.8 \times 1.22 \times 1.0 \times 1.0 \times 0.55=0.554$

\section{Rectangular wide shape nose pillar}

Because the value $(\mathrm{U} / \mathrm{Uc})=0.43$

$(\mathrm{U} / \mathrm{Uc})<1$ then the value of $\mathrm{KI}=2.4 \mathrm{x}(\mathrm{U} / \mathrm{Uc})$

$\mathrm{K}_{\mathrm{I}}=2.4 \times 0.43=1.032$

$\mathrm{K} \sigma=0.8 ; \mathrm{Ks}=0.76 ; \mathrm{K} \alpha=1.0 ; \mathrm{Kdt}=1.0 ; \mathrm{Kd}=0.55$

$\mathrm{Yse}=\mathrm{K}_{1} \mathrm{~K} \sigma \mathrm{Ks} \mathrm{K} \alpha \mathrm{Kdt} \mathrm{K} \mathrm{d}$

$=1,032 \times 0.8 \times 0.76 \times 1.0 \times 1.0 \times 0.55=0.345$

\section{Conclusion}

1. The results of running from the three pillar variations (cylinder, rectangular, rectangular wide shape nose pillar) show that the greatest scour depth occurs at the point of observation of the front side of the pillar.

2. The shape of the pillar is a factor that influences the depth of local scouring around the pillar. Rectangular wide shape nose are the pillars that form the greatest scour depth of the other two pillars (cylinder and rectangular). 
3. The maximum scour depth values on cylinder, rectangular and rectangular wide shape nose at discharge of 1.0 liter/s are $25 \mathrm{~mm}, 30 \mathrm{~mm}$, and $39 \mathrm{~mm}$ respectively.

4. From the scour depth and observation values on the effect of the pillar shape on the local scouring mechanism with three variations of the pillars show that the cylinder pillar has the lowest value for local scour depth, then the cylinder pillar shape is better than the other two shapes to be used as bridge pillar.

\section{References}

[1] Raudkivi, AJ and Ettema, R.: Clear-Water Scour at Cylinder Piers. Journal of Hydraulic Engineering, Vol. 109, No. 3, pp. 338-350. ASCE, New York (1983).

[2] Istiarto: Diktat Geometry Lecture and River View Capacity. Perumka - FT UGM, Yogyakarta (2002)

[3] Yulistiyanto B., Y. and WH Graf Zech,: Free- Surface Flow Around a Cylinder: Shallow - water-Dispersion Modeling with Diffusion. Journal of Hydraulic Engineering, Vol. 124, No.4, pp.419-429. ASCE, New York (1998).

[4] Hanwar, S.: Local Scouring around Bridge Abutments - PPS UGM, Yogyakarta (1999).

[5] Breusers, HNC and Raudkivi, AJ.: Scouring. IAHR Hydraulic Structure Design Mannual, 1 st ed., AA Balkema, Rotterdam (1991).

[6] Melville, BW.: Bridge Abutment Scour In Compound Channel. Journal of Hydraulic Engineering. Vol 121, No. 12, pp. 863-868. ASCE, New York, (1995).

[7] Sucipto and Qudus, N. Local Scour Analysis in Downstream Bed Protection. Journal of Civil Engineering and Planning. Vol. 6, No. 1. UNNES, Semarang (2004).

[8] Rahmadani, S. and Terunajaya . Local Scour Mechanisms with Pillar Shape Variations (Experiments). Vol. 3, No. 2. USU, Medan (2014).

[9] Syarvina and Terunajaya. Local Scour Mechanism On Single Cylinder Pillars With Discharge Variations. Vol. 2, No. 3. USU, Medan (2013).

[10] Triatmodjo, B. Hidraulika I. Beta Offset, Yogyakarta (2003). 